\title{
68
}

\section{The Smile Strike}

The hotel manager wanted to engage 'shoppers', but she met with opposition from the desk clerks. Shoppers are secretly employed by management to pose as customers, clients, passengers, policyholders and so on. Their task is to pass on information to management about the quality of service given by the employees. Generally, service employees regard this as spying and an unfair, dignity-threatening type of quality control. So did the hotel clerks.

When they found out about the hotel manager's plans, they became so angry that they staged a specific form of strike: they refused to smile at the customers. The hotel guests were treated correctly and speedily, but without feeling. They did not get one single smile.

(Fuller and Smith, 1991) 